\title{
A synopsis of current practices in minimally invasive surgery for adult spinal deformity
}

\author{
Aniruddh V. Agrawal ${ }^{1}$, Vinod A. Agrawal ${ }^{2}$, Adit A. Singhal ${ }^{3}$, Adit Maniar ${ }^{4}$
}

\author{
${ }^{1}$ Topiwala National Medical College, ${ }^{2}$ Consultant Orthopaedic Surgeon, Lilavati Hospital, Mumbai, MH, India \\ ${ }^{3}$ Geisinger Commonwealth School of Medicine, Scranton, PA, USA \\ ${ }^{4}$ Dr. Vasantrao Pawar Hospital and Research Centre, Nashik, MH, India
}

Received: 21 April 2017

Revised: 19 May 2017

Accepted: 23 May 2017

\author{
*Correspondence: \\ Dr. Aniruddh V. Agrawal, \\ E-mail: anirudhagrawal25@gmail.com
}

Copyright: $($ ) the author(s), publisher and licensee Medip Academy. This is an open-access article distributed under the terms of the Creative Commons Attribution Non-Commercial License, which permits unrestricted non-commercial use, distribution, and reproduction in any medium, provided the original work is properly cited.

\begin{abstract}
To provide a comprehensive summary of the status, indications and developments in the use of minimally invasive surgery in the field of adult spinal deformity. This study was performed by expert review of literature which has been published and is indexed on PubMed. The most appropriate and recent articles were selected to obtain a consolidation of information and knowledge on use and benefits of minimally invasive surgery in adult spinal deformity. Various MIS techniques have been developed to perform the complex ASD surgeries. These include the transforaminal lateral interbody fusion (TLIF), percutaneous segmental fixation as well as the lateral body interbody fusion (LLIF). It is important for a surgeon to obtain a holistic view of current literature and recommended guidelines on the procedures available for ASD surgeries. Overall, minimally invasive spine surgery has resulted in less use of pain medicine, less blood loss, lower infection rates, less requirement for intensive care, less hospitalization, reduction in physiologic stress, reduction in complication rates, reduction in muscle atrophy and preservation of normal motion with fusion rates being as high as $80-95 \%$. More articles consolidating the vast literature on minimally invasive spine surgery need to be published to allow a surgeon to effectively weight the benefits and drawbacks of it. More research needs to be performed to compare the efficacy of sub-types of minimally invasive spine surgery.
\end{abstract}

Keywords: Adult deformity, Minimally invasive surgery, Review, TLIF, LLIF, ALIF

\section{INTRODUCTION}

Adult spinal deformities refer to a group of symptoms associated with abnormal curvatures in the spinal column. The normal spinal column has natural smooth curves in different regions of the body, when abnormalities occur, these curves become misaligned and exaggerated. The different types of these abnormalities are termed kyphosis, which refers to an abnormally rounded upper back, scoliosis, which refers to an axially rotated and laterally displaced spine and lordosis, which refers to a significant inward curve in the lower back.
While scoliosis is defined as a lateral curvature (Cobb angle) greater than $20^{\circ}$ in adult patient, kyphosis is defined as an increase in the 'roundness' of the thoracic vertebrae above $45^{\circ}$. Over the years there has been a refinement in the classification of scoliosis. The adolescent classification system evolved from the King system to the Lenke system to the most recent, Peking Union Medical College system. The adult classification system evolved from the Aebi system to the SRSSchwabb system. This latest system classifies the scoliosis deformity based on the parameters of sagittal vertical axis (SVA), the pelvic tilt (PT), and the difference between the pelvic incidence (PI) and the 
lumbar lordosis (LL), PI-LL. ${ }^{1}$ This schema involves direction of curve, location of the curve and grouping by age. According to its direction, scoliosis is divided into dextroscoliosis which describes a curve to the right, and levoscoliosis which describes a curve to the left. With respect to the location, it could be a thoracic scoliosis, lumbar scoliosis or a thoracolumbar scoliosis. Scoliosis could be infantile (up to 3 years), juvenile (3 to 9 years), adolescent (10 to 18 years) or adult according to the age of the patient. All these parameters factor in the diagnosis and surgical decision making process.

However, to completely understand the various parameters associated with the diagnosis and treatment of adult scoliosis, it is important to assess spino-pelvic parameters as these have been shown to correlate with the health related quality of life (HRQOL) index..$^{2-5}$ The pelvic morphology remains constant after adolescence and hence recent studies have outlined an important role of the pelvis in influencing spinal alignment and maintaining sagittal balance. For this various parameters have been defined and are mentioned in the following sections. ${ }^{6}$

Pelvic incidence (PI) is considered to be a morphologically fixed and reflects the relationship of the sacrum with respect to the pelvis. ${ }^{6}$ A study has concretized PI's role in estimating lumbar lordosis by computing the formula stating lumbar lordosis (LL) $=$ PI $+9^{\circ}\left( \pm 9^{\circ}\right) .^{7,8}$ Studies have not only found a significant correlation between the PT and the HRQOL index but also determined that PT is indicative of pelvic retroversion in an attempt to compensate for sagittal deformity and it also compensates for decreased LL. ${ }^{7}$ The objective of a pelvic realignment is to obtain a postoperative PT of $<20^{\circ}$. Since PT realignment restores femoral-pelvic-spinal alignment and is shown to correlate with walking tolerance, it should be a part of the surgical planning process. ${ }^{5,7,9,10}$ The SS equates to the PI with the help of a mathematical equation PI $=\mathrm{PT}+\mathrm{SS}$ and as PT increases, the SS decreases. ${ }^{4,5,11,12}$ Normal values of LL range from $40^{\circ}-60^{\circ}$. Every individual has an LL which is dependent on the PI and hence the role of the pelvis in determining the LL cannot be underestimated. ${ }^{6,12,13}$ Studies have demonstrated that a relationship between the PI and LL must be maintained for spino-pelvic balance and that although a spine can be balanced with a low LL as compared to a PI, the PT is often elevated in such cases, signifying a sagittal imbalance. ${ }^{14}$ Pelvic obliquity (PO) is defined as the angle formed between a horizontal reference line and a line drawn between the 2 inferior points of the sacral ala on an anteroposterior radiograph and is an important parameter for surgical planning. ${ }^{11}$ This deformity may be due to discrepancy in leg length due to congenital or acquired conditions or even from a sacropelvic deformity. This may form a compensatory lumbar curve whose correction without the correction of the pelvic obliquity may lead to coronal decompensation. In a secondary obliquity, surgical strategies should be efficiently modified to achieve a relaxation of pelvis in the coronal plane post-operatively. An introduction to all these parameters is important for the diagnosis and the decision making process of correction of the underlying deformity.

Final desired parameters and alignment goals include an SVA of less than $5 \mathrm{~cm}$, a T1 tilt of less than $0^{\circ}$, a PT of less than $20^{\circ}$ and a LL equal to PI $\pm 9^{\circ}$. These parameters and their clinical importance have been further discussed in the following sections. ${ }^{10}$

\section{DIAGNOSIS AND INDICATIONS OF ADULT SPINAL DEFORMITY SURGERY}

The diagnosis of adult spinal deformity is most often based on a general approach of clinical and radiographic findings. The surgeon should also be able to correlate the clinical and the radiographic findings for a complete diagnostic picture.

\section{Symptoms of the patient (clinical diagnosis)}

Degenerative changes in the spine are directly correlated to the age. The disability associated with these changes has shown to cause a significant decrease in the quality of life. ${ }^{15}$ However data has shown that majority of the back pain associated with these degenerative changes is due to structural pathologies such as spinal stenosis and etiologies such as spondylosis or scoliosis and these are what need medical management. ${ }^{16}$ While symptomdriven treatment of the deformity is key, it is important to understand that pain and disability are two different phenomena with differing treatments.

Symptoms of axial pain are most often associated with intervertebral disc degeneration and facet arthrosis. With the degeneration of the disc, the loading of surrounding structures may lead to arthropathy, ligamentous hypertrophy and muscle fatigue. ${ }^{17}$ In such a condition, spinal fusion may be indicated as surgeons have adopted fusion as a method of alleviating pain. The radicular pain usually implies pressure, inflammation or stretch of a nerve root and discectomy, formainotomy and laminectomy are considered a common treatment method for such a condition. ${ }^{17}$ Isthmic spondylisthesis may also warrant an instrumented fusion. ${ }^{18,19}$

The second clinical factor to be considered is disability and is a mechanical impediment that should be considered separately from the pain. Disability caused by pain can be handled through medication and mechanical disability could be managed with the help of external aids. It is important to keep an account of the disability changes in the patient with the help of the Oswestry disability index. ${ }^{20}$

\section{Radiological diagnosis}

It is important to understand that ASD should not be treated solely on radiographic findings, the symptoms in 
terms of pain and disability of the patient are more important and it is not uncommon that the radiological and the clinical findings do not go hand in hand. The SRS-Schwab classification has acknowledged the relationship between the radiological and clinical findings and tries to define radiological goals for surgery. This classification has proven essential to surgical planning of a patient suffering from ASD. ${ }^{21}$ The different parameters associated with this classification method have been mentioned earlier. The clinical importance of these parameters is observed while defining the threshold of disability which is defined as an ODI score greater than 40, an SVA greater than $47 \mathrm{~mm}$, a PT greater than $22^{\circ}$ and the value of PI minus LL greater than $11^{\circ} .^{22}$

\section{Imaging analysis}

While radiographic imaging, a free standing position of the patient involving a natural foot position, forward shoulder flexion and flexion at the elbow to bring fingertips into the cheekbones or the clavicle prevents underestimation of global deformity and helps evaluate the compensatory mechanisms involved. ${ }^{23}$ The radiograph should include the occiput superiorly and the femoral heads inferiorly.

The MRI's are mostly used to identify soft tissue structures and therefore they can easily demarcate disk height and damage, if any, to adjacent soft tissues.

\section{MIS APPROACH}

Traditional "open" scoliosis surgery, although quite successful in its time, was associated with complication rates as high as $41.2 \%$ including major ones such as excessive blood loss (>4 L) and deep wound infection which required re-exploration of the wound. ${ }^{24,25}$ Therefore, there was a need of a more advanced procedure which would decrease the peri-operative morbidity associated with traditional ASD surgery. Minimally Invasive Spine Surgery has proven itself to be that procedure.

\section{Surgery planning}

Operative procedures require certain modifications to meet the unique needs and goals of each patient. Classification schemes, like the MiSLAT algorithm allow the surgeon to classify the surgery into different groups to better plan the surgical procedure and follow the appropriate guidelines. ${ }^{26}$ It is necessary to evaluate beforehand whether a MIS would be appropriate for the procedure or not.

\section{Different approaches}

Minimally invasive spine surgery has become a popular surgical procedure due to its numerous potential advantages which include, reduced length of stay, blood loss and an earlier return to work. Minimally Invasive
Surgery is a term which applies to a broad range of techniques and procedures that are used to achieve the goal of spinal stability. These MIS techniques can either be employed on a stand-alone basis or in combination through three broad categories of surgeries, each one defined by the invasiveness of operation: MIS decompression, circumferential MIS and MIS + open (hybrid surgery). ${ }^{27-29}$

\section{Transforaminal lumbar interbody fusion (TLIF)}

Transforaminal interbody fusion (TLIF), first introduced by Blume and Rojas and later popularized by Harms and Jeszenszky, represents a refinement of the posterior lumbar interbody fusion approach. ${ }^{30,31}$ The technique accesses the disc space unilaterally using a far lateral trajectory through the vertebral foraminal space. This anatomical space, known as Kambin's triangle, is bordered by the articular process, exiting nerve root, and proximal vertebral plate. ${ }^{32,33}$

The most common procedure performed with a posterior approach is the transverse lumbar interbody fusion (TLIF). This procedure has gained a lot of popularity and has been the subject of multiple research studies in the past decade. It has been used to address multiple corrections including local degenerative arthritis, restoring foraminal height, achieving indirect neural decompression and correcting coronal deformity. ${ }^{34,35}$ Multi-level TLIF has proven itself as a promising approach for correction of deformity surgery without the patient having to undergo multiple step surgery. Documented evidence published by Wang showed a remarkable betterment of patient health after the surgery using expandable cages in 25 cases in which 3.2 levels, on an average, were fused. ${ }^{36}$ The postoperative Cobb angle improved from $29.2^{\circ}$ to $9^{\circ}$ while the global lumbar lordosis improved from $27.8^{\circ}$ to $42.6^{\circ}$ and even the SVA improved from $7.4 \mathrm{~cm}$ to $4.3 \mathrm{~cm}$. Even clinically at a oneyear follow up, NPS for leg pain improved from 5.1-1.8 and NPS for back pain improved from 7.6-3.4 while the ODI improved from 44.1 to 24.1 after surgery. Other studies by Jagannathan et al and Yson et al showed significant improvements in focal lordosis and also observed that multi-level TLIF was more effective in correcting overall lumbar lordosis than a single-level surgery. ${ }^{37,38}$ This approach however, due to a small surgical window, limits the degree of discectomy and graft placement that is feasible.

Advancements to the TLIF procedure have been seen in establishment of the Cantilever TLIF (CTLIF) procedure which is used with a structural allograft. Studies have promoted the use of C-TLIF as a way of maintaining lumbar lordosis, avoiding nerve problems and obtaining a positive fusion result. ${ }^{39,40}$ In both these studies, patients showed significant reduction in pain scores, ODI scores and treatment intensity scores. All patients had improvement of radicular pain with no dural tears, neural injury or neuropathic pain. 


\section{Lateral lumbar interbody fusion}

Lateral lumbar interbody fusion (LLIF) was developed on the foundations of the laparoscopic ALIF. The approach involves a retroperitoneal trajectory to the spine..$^{34}$ Access to the disc space is achieved via serial dilatation through the psoas musculature using fluoroscopy and EMG monitoring. The technique provides anterior exposure of the disc while avoiding the great vessels and abdominal cavity.

The use of Standalone lateral MIS surgeries in a pediatric or adolescent patient population is not well established and should be reserved for those patients who are at unacceptably high risk for alternative conventional or MIS combined approaches. ${ }^{41}$ Patients with excessive pain, progressive degeneration and significant comorbidity and osteoporosis should be considered for less invasive interventions. What is especially advantageous in this approach is that it is not a destabilizing technique, unlike the posterior approaches. It also allows a generous discectomy and end-plate preparation allowing placement of larger interbody implant. ${ }^{42}$ This approach also allows access to more levels with a decreased vascular risk and is also advantageous as it preserves the anterior longitudinal ligament (ALL). The evidence of the efficacy of this novel approach however, remains uncertain.

However, certain drawbacks of this new procedure have also been documented. Acosta et al reported a significant improvement of Cobb angle from $21.4^{\circ}$ to $9.7^{\circ}$ postoperatively. However, lumbar lordosis only changed from $42.1^{\circ}$ to $46.2^{\circ}$ despite improvement in interbody height. Overall the global sagittal alignment was unchanged. ${ }^{43}$ Karikari noted a similar improvement in global lordosis of only $5^{0.44}$ Another drawback is that majority of the physiological lumbar lordosis is found at the L5-S1 and L4-L5 levels which are problematic to access with the direct lateral approach. A modification of the technique by resection of the anterior longitudinal ligament has been proposed to enhance sagittal correction. $^{45-47}$

\section{Percutaneous segmental fixation}

While minimally invasive spinal surgeries continue to rise in popularity, emergence of a new technology for minimally invasive placement of percutaneous subfacial pedicle screws and rods has allowed spinal fixation through a limited surgical approach. ${ }^{48,49}$ The technique described by Foley et al shows promising results in the preliminary studies. ${ }^{48}$ This system allows for placement of lumbar pedicle screws and rods through percutaneous stab wounds. In his initial report of 12 patients, paraspinous tissue trauma was greatly minimized. Recently, there have been reports of guide wire-less pedicle screw placements in the thoracic and lumbar spine. This method has shown a $92.7 \%$ success rate and has become a topic of discussion. This technique however, has a steep learning curve and can be difficult to adopt for surgeons who have only been trained in open surgeries. The indications for this procedure are increasing and include degenerative changes, trauma, spinal neoplasia, infection and MIS grafting.

A study by Neel at al evaluated the efficacy of this procedure for lumbar degenerative scoliosis with the help of 12 patient reports. ${ }^{50}$ This study reported a mean blood loss for anterior procedures as $163.89 \mathrm{ml}$ and for posterior pedicle screw fixation as $93.33 \mathrm{ml}$. Cobb Angle improved postoperatively to $6.19^{\circ}$ from $18.93^{\circ}$. Even the post-operative VAS and TIS scores improved to 4.8 from 7.1 and 28 from 56. This study suggested that a combination of three MIS techniques allowed for correction of lumbar degenerative scoliosis with less blood loss and morbidity.

However, certain challenges related to this procedure have been reported. These include changing direction of screw placement following initial pedicle cannulation, difficulties related to L5/S1 screw head proximity, cannulation of small pedicles in the thoracic spine, selection of skin incisions for multi-segmental fixation and insertion of a rod for multi-segmental fixation or the removal of rod after initial placement. ${ }^{51}$

\section{COMPARISON OF DIFFERENT APPROACHES FOR CORRECTION OF ASD}

As mentioned before, there are three broad categories of MIS approaches to adult deformity surgery MIS decompression, circumferential minimally invasive surgery (cMIS) and the hybrid approach.

It is important for the surgeon to know which technique medical literature supports the most. Anand et al reported a case series of 12 patients who underwent the cMIS procedure involving multi-level LLIF combined with posterior percutaneous instrumentation and reported significant improvements in coronal Cobb angle (from $18.93^{\circ}$ to $6.19^{\circ}$ ), however, the effect on sagittal balance and spinopelvic parameters was not well defined. ${ }^{50}$ Comparison between the cMIS and hybrid procedures has showed that hybrid groups demonstrated greater improvement radiographically at the expense of a higher complication rate. ${ }^{27}$ This coincides with reports of Wang et al. who demonstrated a major complication rate of $40 \%$ in patients undergoing hybrid surgery while only $14 \%$ in the cMIS group. ${ }^{52}$ It was also noted that rates of revision surgery in hybrid surgery was almost twice as much when compared to the cMIS group. There is however, no definitive evidence to suggest that any particular approach is overall superior to the others and the decision to use a particular approach should be decided on a caseby-case basis.

One should be acquainted with certain limitations and patient selection considerations that are involved with choosing an MIS approach to the spine. Most surgeons 
reported a ceiling effect of $23^{\circ}, 34^{\circ}$ and $55^{\circ}$ for standalone, cMIS and hybrid groups on coronal Cobb angle and only the hybrid group has shown to have significant improvement in SVA and LL. ${ }^{52}$ The SRSSchwab global alignment modifier has proved to be a great classification took when considering a patient for an MIS approach. Marked sagittal deformity was determined to be PI-LL $>20^{\circ}$, an SVA $>9.5 \mathrm{~cm}$, or a PT $>30^{\circ}$ and cMIS was effective in improving radiographic parameters and quality of life in patients with up to moderate sagittal deformity and not marked deformity. ${ }^{28,53,54}$

A study published by the international spine study group evaluated 20 MIS, 20 hybrid and 20 open surgeries showed a statistically significant increase and operative time and decrease in blood loss in the MIS group when compared to the hybrid and the open groups. No intraoperative complications were reported for the MIS surgery, but $5.3 \%$ for the hybrid group and $25 \%$ for the open group. At least one intra-operative complication occurred in $30 \%, 47 \%$ and $63 \%$ of the MIS, hybrid and open surgeries respectively. This study helps us understand the relationship between the complication rates and the method of surgery that is used. ${ }^{55}$ Another study compared the radiographic results between the three procedures in 184 patients (MIS -42, hybrid -33 and open -109). The MIS group maintained a significantly smaller Cobb angle post-operatively $\left(13.1^{\circ}\right)$ when compared to the hybrid $\left(17.7^{\circ}\right)$ and open $\left(20.4^{0}\right)$ approaches but showed a significantly less change in the Cobb angle before and after the surgery (MIS $-18.8^{\circ}$, hybrid $-26.6^{0}$, open $-22.9^{\circ}$ ). Even the mean change in the $\mathrm{Pi}-\mathrm{LL}$ was the highest in the hybrid group (MIS- $5.5^{\circ}$, hybrid $-20.6^{\circ}$, open $-10.2^{\circ}$ ) and the SVA correction was the greatest for the open group ( MIS $-\leq 1 \mathrm{~mm}$, hybrid -25 $\mathrm{mm}$, open $-33 \mathrm{~mm})$. There was however, no significant difference between the groups in terms of pre- and postoperative mean ODI and Vas scores at the 1 year follow up. In contrast to the previous study, the complication rates were $14 \%$ for MIS, $14 \%$ for hybrid and $45 \%$ for the open group. However, estimated blood loss of the patients was significantly reduced in the MIS approach as compared to hybrid and open techniques. ${ }^{56}$ Other studies have reported that patients who underwent MIS surgery were mobilized earlier compared to open surgery which lead to fewer peri-operative complications and may even lead to reduced length of stay. ${ }^{50,57,58}$

The MIS approach may turn out to be more cost effective than one would traditionally think. Wang et al reported no significant difference in cost in patients undergoing 2level fusions, however in the single-level comparison, an MIS surgery cost USD 70,159 on average but the open surgery costed USD $78,444 .^{59}$

Overall MISS technique has resulted in less use of pain medicine, less blood loss, lower infection rates, less requirement for intensive care, less hospitalization, reduction in physiologic stress, reduction in complication rates, reduction in muscle atrophy and preservation of normal motion with fusion rates being as high as 80$95 \% .^{60-70}$

\section{CURRENT STATE AND FUTURE ENDEAVORS IN MIS FOR ASD}

In a study performed to determine efficacy of the MIS technique through a comparative effectiveness research (CER), on meta-analysis of peri-operative outcome measures of 856 patients, MIS was favored over open surgery, except for the factor of radiation exposure. However, patients lost $260 \mathrm{~mL}$ less blood, were able to ambulate on average 3.5 days faster and were discharges 2.9 days sooner in MIS procedures compared to open. ${ }^{71}$

While surgeons are debating over the efficacy of MIS and open lumbar fusion procedures, compelling evidence for the clinical equivalence of the two techniques exist. However, limitations in study designs of present research prevents strong recommendations being made based on these studies. There also remains concern of the heterogeneity of diagnosis that are part of current studies, which leads to lumping of patients for observing treatments effects and causes decreased reliability of the outcome measures for the purposes of assessing treatment effects.

Radiation exposure to the surgeon has become a rising cause of concern and to that end, multiple papers have been published which suggest the use of fluoronavigation techniques in place of standard fluoroscopy to decrease the exposure to radiation time. Some studies even saw a decrease from 147 to $57 \mathrm{sec}$ and 177 to 75 sec. $^{72,73}$

However, it is important to understand that each technique has its positive and negative aspects and one should consider all the benefits and risks related to a particular technique when tailoring your procedure for an individual. Further evaluation on the efficacy of MIS and its benefits over other procedures is required. However, as surgical techniques and intra-operative technologies evolve over time, MIS procedures for the spine will be the gold standard for correction of ASD.

Funding: No funding sources

Conflict of interest: None declared

Ethical approval: Not required

\section{REFERENCES}

1. Akinbo OC, Tu T-H, Ziewacz JE, Mummaneni PV. Classification Schema for Scoliosis. In: Wang YM, Lu Y, Anderson GD, Mummaneni VP, eds. Minimally Invasive Spinal Deformity Surgery: An Evolution of Modern Techniques. Vienna: Springer Vienna; 2014: 11-20.

2. Bridwell KH, Glassman S, Horton W, Shaffrey C, Schwab F, Zebala LP, et al. Does treatment (nonoperative and operative) improve the two-year 
quality of life in patients with adult symptomatic lumbar scoliosis: a prospective multicenter evidence-based medicine study. Spine. 2009;34(20):2171-8.

3. Glassman SD, Bridwell K, Dimar JR, Horton W, Berven S, Schwab F. The impact of positive sagittal balance in adult spinal deformity. Spine. 2005;30(18):2024-9.

4. Lafage V, Bharucha NJ, Schwab F, Hart RA, Burton $\mathrm{D}$, Boachie-Adjei $\mathrm{O}$, et al. Multicenter validation of a formula predicting postoperative spinopelvic alignment. J Neurosurg Spine. 2012;16(1):15-21.

5. Lafage V, Schwab F, Patel A, Hawkinson N, Farcy JP. Pelvic tilt and truncal inclination: two key radiographic parameters in the setting of adults with spinal deformity. Spine. 2009;34(17):599-606.

6. Mac-Thiong JM, Berthonnaud E, Dimar JR, 2nd, Betz RR, Labelle H. Sagittal alignment of the spine and pelvis during growth. Spine. 2004;29:1642-7.

7. Schwab F, Lafage V, Patel A, Farcy JP. Sagittal plane considerations and the pelvis in the adult patient Sagittal alignment of spine and pelvis regulated by pelvic incidence: standard values and prediction of lordosis. Spine. 2009;34:1828-33.

8. Boulay C, Tardieu C, Hecquet J, Benaim C, Mouilleseaux B, Marty C, et al. Sagittal alignment of spine and pelvis regulated by pelvic incidence: standard values and prediction of lordosis. Eur Spine J. 2006;15(4):415-22.

9. Skalli W, Zeller RD, Miladi L, Bourcereau G, Savidan M, Lavaste F, et al. Importance of pelvic compensation in posture and motion after posterior spinal fusion using $\mathrm{CD}$ instrumentation for idiopathic scoliosis. Spine. 2006;31:359-66.

10. Schwab F, Patel A, Ungar B, Farcy JP, Lafage V. Adult spinal deformity-postoperative standing imbalance: how much can you tolerate? An overview of key parameters in assessing alignment and planning corrective surgery Importance of pelvic compensation in posture and motion after posterior spinal fusion using $\mathrm{CD}$ instrumentation for idiopathic scoliosis. Spine. 2010;35:2224-31.

11. Ames CP, Smith JS, Scheer JK, Bess S, Bederman $\mathrm{SS}$, Deviren $\mathrm{V}$, et al. Impact of spinopelvic alignment on decision making in deformity surgery in adults: A review. J Neurosurg Spine. 2012;16(6):547-64.

12. Berthonnaud E, Dimnet J, Roussouly P, Labelle H. Analysis of the sagittal balance of the spine and pelvis using shape and orientation parameters. J Spinal Disord Tech. 2005;18(1):40-7.

13. Roussouly P, Gollogly S, Berthonnaud E, Dimnet J. Classification of the normal variation in the sagittal alignment of the human lumbar spine and pelvis in the standing position. Spine. 2005;30(3):346-53.

14. Neal CJ, McClendon J, Halpin R, Acosta FL, Koski $\mathrm{T}$, Ondra SL. Predicting ideal spinopelvic balance in adult spinal deformity. J Neurosurg Spine. 2011;15(1):82-91.
15. Cheng JS, Forbes J, Wong C, Perry E. The Epidemiology of Adult Spinal Deformity and the Aging Population. In: Wang YM, Lu Y, Anderson GD, Mummaneni VP, eds. Minimally Invasive Spinal Deformity Surgery: An Evolution of Modern Techniques. Vienna: Springer Vienna; 2014: 3-10.

16. Deyo RA, Mirza SK, Martin BI. Error in trends, major medical complications, and charges associated with surgery for lumbar spinal stenosis in older adults. JAMA. 2011;306(10):1088.

17. EC B, WF L, AJ B, SA K. Anatomy of nerve root compression, nerve root tethering, and spinal instability spine surgery: techniques, complication avoidance, and management. 2nd Edition. Philadephia: Saunders elsevier; 2005.

18. Williams RW. Microcervical foraminotomy. A surgical alternative for intractable radicular pain. Spine. 1983;8(7):708-16.

19. de Loubresse CG, Bon T, Deburge A, Lassale B, Benoit M. Posterolateral fusion for radicular pain in isthmic spondylolisthesis. Clin Orthop Relat Res. 1996;323:194-201.

20. Fairbank JC, Couper J, Davies JB, O'Brien JP. The Oswestry low back pain disability questionnaire. Physiotherapy. 1980;66(8):271-3.

21. Deyo RA, Cherkin DC, Ciol MA. Adapting a clinical comorbidity index for use with ICD-9-CM administrative databases. J Clin Epidemiol. 1992;45(6):613-9.

22. Schwab FJ, Bess S, Blondel B, Hostin R, Shaffrey CI, Smith JS, et al. Combined Assessment of Pelvic Tilt, Pelvic Incidence/Lumbar Lordosis Mismatch and Sagittal Vertical Axis Predicts Disability in Adult Spinal Deformity: A Prospective Analysis. Spine J Meeting Abstracts. 2011: 65.

23. Horton WC, Brown CW, Bridwell KH, Glassman $\mathrm{SD}$, Suk SI, Cha CW. Is there an optimal patient stance for obtaining a lateral 36" radiograph? A critical comparison of three techniques. Spine. 2005;30:427-33.

24. Yadla S, Maltenfort MG, Ratliff JK, Harrop JS. Adult scoliosis surgery outcomes: a systematic review. Neurosurg Focus. 2010;28(3):3.

25. Schwab FJ, Hawkinson N, Lafage V, Smith JS, Hart $\mathrm{R}$, Mundis G, et al. Risk factors for major perioperative complications in adult spinal deformity surgery: a multi-center review of 953 consecutive patients. Eur Spine J. 2012;21(12):2603-10.

26. Mummaneni PV, Wang MY, Silva FE, et al. The MiSLAT Algorithm: Minimally Invasive Evaluation and Treatment for Adult Degenerative Deformity. In: Wang YM, Lu Y, Anderson GD, Mummaneni VP, eds. Minimally Invasive Spinal Deformity Surgery: An Evolution of Modern Techniques. Vienna: Springer Vienna; 2014: 67-74.

27. Park P, Wang MY, Lafage V, Nguyen S, Ziewacz J, Okonkwo DO, et al. Comparison of two minimally invasive surgery strategies to treat adult spinal deformity. J Neurosurg Spine. 2015;22(4):374-80. 
28. Mundis G, Uribe JS, Mummaneni PV, Anand N. 172 A Critical Analysis of Sagittal Plane Deformity Correction With Minimally Invasive Surgery: A 2Year Follow-up Study of Deformity Patients Categorized by the SRS-Schwab Classification. Neurosurgery. 2015;62:222-3.

29. Mummaneni PV, Shaffrey CI, Lenke LG, Park P, Wang MY, La Marca F, et al. The minimally invasive spinal deformity surgery algorithm: a reproducible rational framework for decision making in minimally invasive spinal deformity surgery. Neurosurg Focus. 2014;36(5):6.

30. Blume HG. Unilateral posterior lumbar interbody fusion: simplified dowel technique. Clin Orthop Relat Res. 1985;193:75-84.

31. Harms JG, Jeszenszky D. Die posteriore, lumbale, interkorporelle Fusion in unilateraler transforaminaler Technik. Oper Orthop Traumatol. 1998;10(2):90-102.

32. Kambin P. Arthroscopic microdiskectomy. Mt Sinai J Med. 1991;58(2):159-64.

33. Kambin P, Sampson S. Posterolateral percutaneous suction-excision of herniated lumbar intervertebral discs. Report of interim results. Clin Orthop Relat Res. 1986;207:37-43.

34. Ozgur BM, Aryan HE, Pimenta L, Taylor WR. Extreme Lateral Interbody Fusion (XLIF): a novel surgical technique for anterior lumbar interbody fusion. Spine J. 2006;6(4):435-43.

35. Sharma AK, Kepler CK, Girardi FP, Cammisa FP, Huang RC, Sama AA. Lateral lumbar interbody fusion: clinical and radiographic outcomes at 1 year: a preliminary report. J Spinal Disord Tech. 2011;24(4):242-50.

36. Wang MY. Improvement of sagittal balance and lumbar lordosis following less invasive adult spinal deformity surgery with expandable cages and percutaneous instrumentation. J Neurosurg Spine. 2013;18(1):4-12.

37. Jagannathan J, Sansur CA, Oskouian RJ, Fu KM, Shaffrey CI. Radiographic restoration of lumbar alignment after transforaminal lumbar interbody fusion. Neurosurgery. 2009;64(5):955-63.

38. Yson SC, Santos ER, Sembrano JN, Polly DW. Segmental lumbar sagittal correction after bilateral transforaminal lumbar interbody fusion. J Neurosurg Spine. 2012;17(1):37-42.

39. Anand N, Hamilton JF, Perri B, Miraliakbar H, Goldstein T. Cantilever TLIF with structural allograft and RhBMP2 for correction and maintenance of segmental sagittal lordosis: longterm clinical, radiographic, and functional outcome. Spine. 2006;31(20):748-53.

40. Hioki A, Miyamoto K, Hosoe H, Sugiyama S, Suzuki N, Shimizu K. Cantilever transforaminal lumbar interbody fusion for upper lumbar degenerative diseases (minimum 2 years follow up). Yonsei Med J. 2011;52(2):314-21.

41. Ahmadian A, Bach K, Bolinger B, Malham GM, Okonkwo DO, Kanter AS, et al. Stand-alone minimally invasive lateral lumbar interbody fusion: multicenter clinical outcomes. J Clin Neurosci. 2015;22(4):740-6.

42. Eck JC, Hodges S, Humphreys SC. Minimally invasive lumbar spinal fusion. J Am Acad Orthop Surg. 2007;15(6):321-9.

43. Acosta FL, Liu J, Slimack N, Moller D, Fessler R, Koski T. Changes in coronal and sagittal plane alignment following minimally invasive direct lateral interbody fusion for the treatment of degenerative lumbar disease in adults: a radiographic study. J Neurosurg Spine. 2011;15(1):92-6.

44. Karikari IO, Nimjee SM, Hardin CA, Hughes BD, Hodges TR, Mehta AI, et al. Extreme lateral interbody fusion approach for isolated thoracic and thoracolumbar spine diseases: initial clinical experience and early outcomes. J Spinal Disord Tech. 2011;24(6):368-75.

45. Akbarnia BA, Mundis GM, Moazzaz P, Kabirian N, Bagheri R, Eastlack RK, et al. Anterior column realignment (ACR) for focal kyphotic spinal deformity using a lateral transpsoas approach and ALL release. J Spinal Disord Tech. 2014;27(1):2939.

46. Deukmedjian AR, Dakwar E, Ahmadian A, Smith DA, Uribe JS. Early outcomes of minimally invasive anterior longitudinal ligament release for correction of sagittal imbalance in patients with adult spinal deformity. Scientific World J. 2012;2012:789698.

47. Deukmedjian AR, Le TV, Baaj AA, Dakwar E, Smith DA, Uribe JS. Anterior longitudinal ligament release using the minimally invasive lateral retroperitoneal transpsoas approach: a cadaveric feasibility study and report of 4 clinical cases. J Neurosurg Spine. 2012;17(6):530-9.

48. Foley KT, Gupta SK. Percutaneous pedicle screw fixation of the lumbar spine: preliminary clinical results. J Neurosurg. 2002;97(1):7-12.

49. Anderson DG, Samartzis D, Shen FH, Tannoury C. Percutaneous instrumentation of the thoracic and lumbar spine. Orthop Clin North Am. 2007;38(3):401-8.

50. Anand N, Baron EM, Thaiyananthan G, Khalsa K, Goldstein TB. Minimally invasive multilevel percutaneous correction and fusion for adult lumbar degenerative scoliosis: a technique and feasibility study. J Spinal Disord Tech. 2008;21(7):459-467.

51. Mobbs RJ, Sivabalan P, Li J. Technique, challenges and indications for percutaneous pedicle screw fixation. J Clin Neurosci. 2011;18(6):741-9.

52. Wang MY, Mummaneni PV, Fu KM, Williams S, Mummaneni PV, Sherman JD. Less invasive surgery for treating adult spinal deformities: ceiling effects for deformity correction with 3 different techniques. Neurosurg Focus. 2014;36(5):12.

53. Lowe T, Berven SH, Schwab FJ, Bridwell KH. The SRS classification for adult spinal deformity: 
building on the King/Moe and Lenke classification systems. Spine. 2006;31(19):119-25.

54. Smith JS, Klineberg E, Schwab F, Shaffrey CI, Moal B, Ames CP, et al. Change in classification grade by the SRS-Schwab Adult Spinal Deformity Classification predicts impact on health-related quality of life measures: prospective analysis of operative and nonoperative treatment. Spine. 2013;38(19):1663-71.

55. Uribe JS, Deukmedjian AR, Mummaneni PV, Fu $\mathrm{KM}$, Mundis GM Jr, Okonkwo DO, et al. Complications in adult spinal deformity surgery: an analysis of minimally invasive, hybrid, and open surgical techniques. Neurosurg Focus. 2014;36(5):15.

56. Haque RM, Mundis GM, Ahmed Y, El Ahmadieh TY, Wang MY, Mummaneni PV, et al. Comparison of radiographic results after minimally invasive, hybrid, and open surgery for adult spinal deformity: a multicenter study of 184 patients. Neurosurg Focus. 2014;36(5):13.

57. Park P, La Marca F. Combined "hybrid" open and minimally invasive surgical correction of adult thoracolumbar scoliosis: a retrospective cohort study. Neurosurgery. 2013;72(2):151-9.

58. Wang MY, Mummaneni PV. Minimally invasive surgery for thoracolumbar spinal deformity: initial clinical experience with clinical and radiographic outcomes. Neurosurg Focus. 2010;28(3):9.

59. Wang J, Zhou Y, Feng Zhang Z, Qing Li C, Jie Zheng W, Liu J. Comparison of the clinical outcome in overweight or obese patients after minimally invasive versus open transforaminal lumbar interbody fusion. J Spinal Disord Tech. 2014;27(4):202-6.

60. Fessler RG, Khoo LT. Minimally invasive cervical microendoscopic foraminotomy: an initial clinical experience. Neurosurgery. 2002;51(5):37-45.

61. O'Toole JE, Sheikh H, Eichholz KM, Fessler RG, Perez-Cruet MJ. Endoscopic posterior cervical foraminotomy and discectomy. Neurosurg Clin $\mathrm{N}$ Am. 2006;17(4):411-22.

62. Khoo LT, Palmer S, Laich DT, Fessler RG. Minimally invasive percutaneous posterior lumbar interbody fusion. Neurosurgery. 2002;51(5):166-81.

63. Peng CW, Yue WM, Poh SY, Yeo W, Tan SB. Clinical and radiological outcomes of minimally invasive versus open transforaminal lumbar interbody fusion. Spine. 2009;34(13):1385-9.
64. O'Toole JE, Eichholz KM, Fessler RG. Surgical site infection rates after minimally invasive spinal surgery. J Neurosurg Spine. 2009;11(4):471-6.

65. Eichholz KM, O'Toole JE, Fessler RG. Thoracic microendoscopic discectomy. Neurosurg Clin N Am. 2006;17(4):441-6.

66. Huang TJ, Hsu RW, Li YY, Cheng CC. Less systemic cytokine response in patients following microendoscopic versus open lumbar discectomy. J Orthop Res. 2005;23(2):406-11.

67. Rosen DS, O'Toole JE, Eichholz KM, et al. Minimally invasive lumbar spinal decompression in the elderly: outcomes of 50 patients aged 75 years and older. Neurosurgery. 2007;60(3):503-10.

68. Bresnahan L, Fessler RG, Natarajan RN. Evaluation of change in muscle activity as a result of posterior lumbar spine surgery using a dynamic modeling system. Spine. 2010;35(16):761-7.

69. Bresnahan L, Ogden AT, Natarajan RN, Fessler RG. A biomechanical evaluation of graded posterior element removal for treatment of lumbar stenosis: comparison of a minimally invasive approach with two standard laminectomy techniques. Spine. 2009;34(1):17-23.

70. Lauber S, Schulte TL, Liljenqvist U, Halm H, Hackenberg L. Clinical and radiologic 2-4-year results of transforaminal lumbar interbody fusion in degenerative and isthmic spondylolisthesis grades 1 and 2. Spine. 2006;31(15):1693-8.

71. Goldstein CL, Rampersaud YR. Clinical Research in MIS Surgery: Current State and Future Challenges. In: Wang YM, Lu Y, Anderson GD, Mummaneni VP, eds. Minimally Invasive Spinal Deformity Surgery: An Evolution of Modern Techniques. Vienna: Springer Vienna; 2014: 371385.

72. Kim CW, Lee YP, Taylor W, Oygar A, Kim WK. Use of navigation-assisted fluoroscopy to decrease radiation exposure during minimally invasive spine surgery. Spine J. 2008;8(4):584-90.

73. Gebhard FT, Kraus MD, Schneider E, Liener UC, Kinzl L, Arand M. Does computer-assisted spine surgery reduce intraoperative radiation doses? Spine. 2006;31(17):2024-8.

Cite this article as: Agrawal AV, Agrawal VA, Singhal AA, Maniar A. A synopsis of current practices in minimally invasive surgery for adult spinal deformity. Int J Res Orthop 2017;3:643-50. 